\title{
Genetic diversity of gac [Momordica cochinchinensis (Lour.) Spreng] accessions collected from Mekong delta of Vietnam revealed by RAPD markers
}

\author{
Pham Duc Toan $^{* 1}$, Vo Thi Thuy Hue ${ }^{1}$, Huynh Van Biet ${ }^{1}$, Bui Minh Tri $^{1}$, Bui Cach Tuyen ${ }^{2}$ \\ ${ }^{1}$ Research Institute for Biotechnology and Environment; Nong Lam University, Ho Chi Minh city, Vietnam \\ ${ }^{2}$ Faculty of Environment and Natural Resources - Nong Lam University, Ho Chi Minh city, Vietnam
}

\section{"Corresponding author: phamductoan@hcmuaf.edu.vn}

\begin{abstract}
Gac (Momordica cochinchinensis (Lour.) Spreng) $(2 \mathrm{n}=28)$ belongs to the Cucurbitaceae family. It is indigenous throughout in Vietnam as well as in South East Asia. To estimate the genetic diversity, 20 gac accessions collected in Mekong river delta were analyzed using 10 RAPD primers. Total of 126 fragments were obtained from ten RAPD primers, with 114 polymorphic fragments, and average of 11.4 fragments per primer. The high level of polymorphism $(90.4 \%)$ was found across 20 gac accessions. The high est Nei's gene diversity value among gac accessions was $\mathrm{H}=0.40$, and the lowest was $\mathrm{H}=0.29$ with a mean of 0.36 . The highest Shannon diversity index value among gac accessions was $\mathrm{H}^{\prime}=0.58$ and the lowest was $\mathrm{H}^{\prime}=0.46$ with an average of 0.53 . Cluster analysis for genetic relationship between accessions displayed that 20 gac accessions grouped into four main clusters which genetic distance coefficient ranged from 0.29 to 0.64 and with an average of 0.54 . There were defined groups according to their locations. According to these results, RAPD technique can be useful tool in genetic diversity evaluation of gac. The information achieved could also be useful for gac breeding program, cultivar differentiation and conservation.
\end{abstract}

Keywords: Cluster analysis, Gac, genetic distance, Momordica, Polymorphism.

\section{Introduction}

Spiny bitter gourd or Gac (Momordica cochinchinensis (Lour.) Spreng) $(2 \mathrm{n}=28)$ belongs to the Cucurbitaceae family. It is indigenous throughout in Vietnam as well as in South East Asia (Wimalasiri et al., 2016). The fruit is called gac in Vietnam, Fakkao in Thailand, Moc-Niet-Tu in China, Bhat Kerala in India and Makkao in Laos (Kubola and Siriamornpun, 2011). Gac fruit has been used as food and for pharmaceutical purpose (Iwamoto et al., 1985; Kubola and Siriamornpun, 2011). Gac aril is cooked along with rice to extract its red pigments and flavor oil from gac to rice for making "xoi gac" in Vietnam. Gac seed composition is of interest, because of its used in traditional Chinese medicine (Ishida et al., 2004). Recently, a pentacyclic triterpenoid ester as a medicine was isolated from the gac seeds (De Shan et al., 2001). Gac aril contained $175 \mu \mathrm{g}$ of $\beta$-carotene and $802 \mu \mathrm{g}$ of lycopene/g of fresh weight (Vuong et al., 2002). Lycopene is of interest, because of the correlation of reduced risk of certain cancers, such as prostate and lung (Gerster, 1997; Giovannucci, 1999; Michaud et al., 2000; Giovannucci et al., 2002). The gac aril contains high oil content and fatty acid compositions, which $69 \%$ are unsaturated and $35 \%$ of those are polyunsaturated fatty acids, and also contains the highest amount of $\beta$-carotene and lycopene (Aoki et al., 2002; Vuong and King, 2003; Vuong et al., 2006).

The crop has been cultivated in various ecological regions of Vietnam for many of years. But, there are a few studies on genetic diversity of this crop in Vietnam. The lack of information available on the genetic diversity of gac is a barrier to select genetic material for an efficient breeding program. Information on genetic diversity and relationships among populations is important for plant breeding programs as it helps to select the right genetic material to be used (Ganesh and Thangavelu, 1995). Genetic diversity in crop species can be determined by using the agro-morphological as well as biochemical and molecular markers (Koornneef, 1990; Reiter et al., 1992; Liu, 1997; Dey et al., 2006; Geleta et al., 2008; Behera et al., 2012; Bootprom et al., 2012). However, the use of agro-morphological markers is associated with a strong influenced from environmental factors. DNA markers overcome this limitation and its markers provide a relatively unbiased estimation of genetic diversity and establish genetic relationship more precisely than agro-morphological markers (Soller and Beckmann, 1983).

Random amplified polymorphic DNA (RAPD) have been widely used in genetic diversity studies in species in which there is a lack of DNA sequence information. This technique has advantage such as low development cost, low level of training and low cost for assay (Karp et al., 1997). RAPD markers have been used to assess genetic diversity among the species of sesame (Bhat et al., 1999; Ercan et al., 2004; Pham et al., 2009), bitter gourd (Dey et al., 2006), spine gourd (Rasul et al., 2007), ash gourd (Sureja et al., 2006), pumpkin (Gwanama et al., 2000), gac (Bootprom et al., 2012; Wimalasiri et al., 2016). The purpose of this study was to evaluate genetic diversity of gac accessions collected from Mekong delta of Vietnam by using RAPD markers. 


\section{Results and Discussion}

\section{Polymorphic RAPD markers for M. cochinchinensis}

Gac (Momordica cochinchinensis (Lour.) Spreng) is native growing in Vietnam for a long time. And nowadays, it was concerned because of its nutrition and medicinal compositions. This present study is one of few report of molecular genetic diversity for gac in Vietnam. Twenty gac accessions collected in Mekong delta of Vietnam were analyzed (Table 1 and Fig. 1). Total of 10 primers amplified 126 bands, including 114 polymorphic bands and 12 monomorphic bands across the 20 gac accessions with an average polymorphism of 11.4 bands per primer. The number of band per primer varied from 9 to 16 with an average of 12.6 bands per primer. The level of polymorphism included by individual primer ranged from $72.7 \%$ to $100 \%$. The highest polymorphism level $(100 \%)$ was displayed when using four primers OPF01, OPF07, OPC20 and OPC15. The lowest polymorphism level $(72.7 \%)$ was obtained with primer OPF10. The average polymorphism level was $90.4 \%$. The size of the amplification products varied from $200 \mathrm{bp}$ to $3 \mathrm{~kb}$. The results are presented in Table 2 and a representative agarose gel picture is showed in Fig. 2. Genetic diversity in gac can be studied using few methods such as agromorphological markers (Sanwal et al., 2007), RAPD markers (Bharathi et al., 2012; Bootprom et al., 2012; Wimalasiri et al., 2016). However, the use of agro-morphological markers is associated with a strong influence from environmental factors. Molecular markers overcome this limitation. Since a few DNA information in gac is a barrier to choose molecular markers for genetic diversity study. RAPD markers are one of priorities to choose because of it does not rely on previous knowledge of DNA sequencing.

In the present study, ten RAPD markers were used for assessing genetic diversity and establishing dendrogram among gac accessions collected in Mekong delta, Vietnam. This study detected a high level of polymorphism for gac accessions collected in Mekong delta. The level of polymorphism was $90.4 \%$ among 20 gac accessions. This was lower than the level of polymorphism (99\%) reported earlier in gac genotypes collected in Thailand and Vietnam by Bootprom et al. (2012). It was also lower than the $98.7 \%$ of polymorphism reported by Wimalasiri et al. (2016) from a study of gac collected in Vietnam, Thailand and Australia. In contrast, this was higher than the level of polymorphism $(36.5 \%)$ reported in an analysis of genetic diversity in Indian bitter gourd by Dey et al. (2006). The results were in agreement with previous gac study, which high polymorphic markers $(100 \%)$ were found with primers OPC15, OPC20, OPF01, OPF07 (Bootprom et al., 2012).

\section{Genetic diversity and cluster analysis}

The genetic diversity of 20 gac accessions was estimated by using 10 RAPD primers. A high genetic diversity was observed among the 20 gac accessions, with an average of 0.54. Gac plant is a crossing pollinated, because gac is a monoecious plant bearing either male and female flowers on the same plant. Hence, the out-crossing of gac among plant and other plants could explain the high genetic variability observed. Ten RAPD markers detected enough genetic diversity among $20 \mathrm{gac}$ accessions to allow for complete differentiation. Shannon diversity index $\left(\mathrm{H}^{\prime}\right)$ and Nei's gene diversity $(\mathrm{H})$ for RAPD variation were estimated for the 20 gac accessions and for each primer. The highest Nei's gene diversity value among gac accessions was $\mathrm{H}=0.40$, and the lowest was $\mathrm{H}=0.29$ with a mean 0.36 . The highest Shannon diversity index value among gac accessions was $\mathrm{H}^{\prime}=0.58$ and the lowest was $\mathrm{H}^{\prime}=0.46$ with an average of 0.53 (shown in table 2). Genetic distance coefficient ranged from 0.29 to 0.64 and with an average of 0.54 (Fig. 3). Some previous studies reported on the use of RAPD markers for estimating genetic diversity of Momordica cochinchinensis as well as Momordica genus. These results were in agreement with previous other studies based on RAPD markers which had reported high genetic diversity in gac (Bootprom et al., 2012; Wimalasiri et al., 2016). Bootprom et al. (2012) reported that high genetic diversity $(0.63-0.90)$ was found in gac collected from Thailand and Vietnam by using 11 RAPD markers. Recently, genetic diversity of gac was reported by Wimalasiri et al. (2016), a high genetic diversity (0.03 1.65) was revealed in gac accessions collected from Thailand, Vietnam and Australia by using 5 RAPD markers. Dey et al. (2006) reported high genetic diversity between 38 genotypes of Indian Momordica charantia L. using 29 RAPD markers. High genetic variation of Indian Momordica spp. genotypes were also revealed by using 21 RAPD markers (Bharathi et al., 2012). In other crops, the use of the similar number of RAPD markers assessing genetic variation was reported. Mujaju et al. (2010) determined a genetic diversity of watermelon using 10 RAPD markers. In addition, Pham et al. (2009); Rafii et al. (2012) reported a high genetic diversity of Sesamum indicum and Jatropha curcas with 10 and 11 RAPD markers, respectively.

A dendrogram was generated using UPGMA cluster analysis, and genetic distance among the 20 gac accessions ranged from 0.29 to 0.64 . The dendrogram divided the $20 \mathrm{gac}$ accessions into four main groups at genetic distance mean 0.54 (Fig. 3). Cluster I was the biggest group included two sub-groups $\mathrm{Ia}$ and $\mathrm{Ib}$, that were gathered at 0.51 distance. Sub-group Ia composed of 7 accessions, G-MKd01, GMKd09, G-MKd03, G-MKd07, G-MKd17, G-MKd21 and G-MKd19 were joined at 0.475 distance. Sub-group Ib contained 8 accessions namely G-MKd02, G-MKd04, GMKd08, G-MKd11, G-MKd15, G-MKd10, G-MKd18, GMKd16 at 0.50 distance. Cluster II and cluster III consisted of only two accessions G-MKd12, G-MKd14 at 0.47 and GMKd20, G-MKd22 at 0.50 distances, respectively. The last cluster, group IV consisted of only one accession G-MKd24. There were defined groups according to their locations. Based on dendrogram for cluster analysis, gac accessions from the same location were found to have a close genetic relationship, for example group II (G-MKd12, G-MKd14) and group III (G-MKd20, G-MKd22) from Kien Giang and An Giang provinces, respectively. Interestingly, two accessions G-MKd03 from Can Tho province and G-MKd07 from Dong Thap province were found to group together in the same sub-cluster Ia (Fig. 3). A close relation of these two accessions could be explained as a consequence of exchange by farmers between Can Tho and Dong Thap neighborhood. The results were in agreement with previous observation of Stankiewicz et al. (2001). The authors found that human factor has previously been shown to be responsible for the lack of correlation between genetic and geographical distance in some case (Stankiewicz et al., 2001).

\section{Materials and Methods}

\section{Plant material and DNA extraction}

Twenty gac accessions collected from various locations in Mekong delta of Vietnam were used for this study. The accession name codes for the accessions used in this study 
Table 1. List of 20 gac (Momordica cochinchinensis) accessions used in this study.

\begin{tabular}{|c|c|c|c|c|c|}
\hline ID & $\begin{array}{l}\text { Accession } \\
\text { name code }\end{array}$ & $\begin{array}{c}\text { Place of collection } \\
\text { (province) }\end{array}$ & Latitude (GPS) & Altitude (m) & Region \\
\hline 1 & G-MKd01 & Can Tho & $10.02 .22 \mathrm{~N} 105.47 .28 \mathrm{E}$ & 3 & Mekong delta \\
\hline 2 & G-MKd02 & Can Tho & $10.03 .12 \mathrm{~N} 105.46 .44 \mathrm{E}$ & 3 & Mekong delta \\
\hline 3 & G-MKd03 & Can Tho & $10.08 .50 \mathrm{~N} 105.38 .25 \mathrm{E}$ & 2 & Mekong delta \\
\hline 4 & G-MKd04 & Can Tho & $10.17 .31 \mathrm{~N} 105.30 .51 \mathrm{E}$ & 3 & Mekong delta \\
\hline 5 & G-MKd07 & Dong Thap & $10.25 .53 \mathrm{~N} 105.38 .15 \mathrm{E}$ & 4 & Mekong delta \\
\hline 6 & G-MKd08 & Dong Thap & $10.28 .53 \mathrm{~N} 105.34 .47 \mathrm{E}$ & 10 & Mekong delta \\
\hline 7 & G-MKd09 & Kien Giang & $10.28 .53 \mathrm{~N} 105.34 .47 \mathrm{E}$ & 10 & Mekong delta \\
\hline 8 & G-MKd10 & KienGiang & $10.02 .00 \mathrm{~N} 105.05 .41 \mathrm{E}$ & 5 & Mekong delta \\
\hline 9 & G-MKd11 & Kien Giang & $10.05 .14 \mathrm{~N} 105.03 .06 \mathrm{E}$ & 5 & Mekong delta \\
\hline 10 & G-MKd12 & Kien Giang & $10.08 .56 \mathrm{~N} 104.36 .28 \mathrm{E}$ & 24 & Mekong delta \\
\hline 11 & G-MKd14 & Kien Giang & $10.11 .12 \mathrm{~N} 104.55 .12 \mathrm{E}$ & 1 & Mekong delta \\
\hline 12 & G-MKd15 & Kien Giang & 9.56.51N 105.07.23E & 1 & Mekong delta \\
\hline 13 & G-MKd16 & KienGiang & 9.56.51N 105.07.23E & 1 & Mekong delta \\
\hline 14 & G-MKd17 & Kien Giang & $9.58 .34 \mathrm{~N} 105.06 .16 \mathrm{E}$ & 3 & Mekong delta \\
\hline 15 & G-MKd18 & Kien Giang & $10.15 .05 \mathrm{~N} 104.49 .14 \mathrm{E}$ & 5 & Mekong delta \\
\hline 16 & G-MKd19 & An Giang & $10.20 .23 \mathrm{~N} 105.28 .05 \mathrm{E}$ & 4 & Mekong delta \\
\hline 17 & G-MKd20 & An Giang & $10.22 .14 \mathrm{~N} 105.24 .57 \mathrm{E}$ & 9 & Mekong delta \\
\hline 18 & G-MKd21 & An Giang & $10.24 .07 \mathrm{~N} 105.24 .23 \mathrm{E}$ & 2 & Mekong delta \\
\hline 19 & G-MKd22 & An Giang & $10.9 .15 \mathrm{~N} 105.20 .36 \mathrm{E}$ & 4 & Mekong delta \\
\hline 20 & G-MKd24 & An Giang & $10.23 .53 \mathrm{~N} 105.29 .46 \mathrm{E}$ & 3 & Mekong delta \\
\hline
\end{tabular}

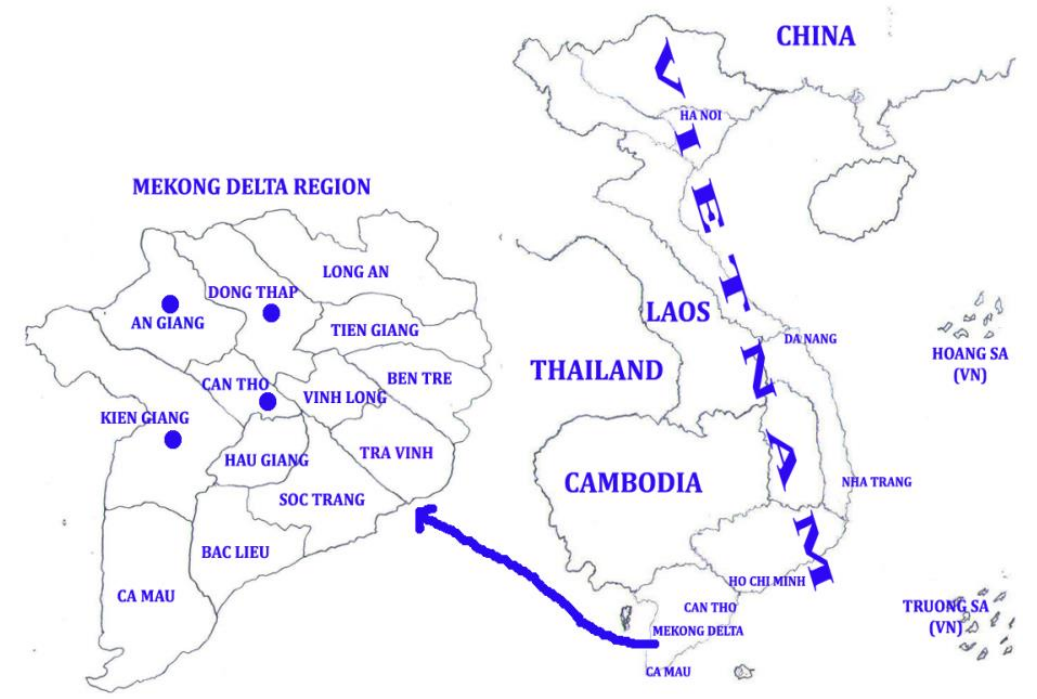

Fig 1. Map of Mekong delta showing collection zones of gac accessions used in this study.

Table 2. List of selected primers used in the RAPD analysis and the number of total fragments, number of polymorphic fragments, percent polymorphism, estimated molecular size range, Nei's gene diversity and Shannon information index.

\begin{tabular}{llcccccc}
\hline Primer & Sequence $\left(5^{\prime}-3^{\prime}\right)$ & TF & PF & \% of P & MSR (bp) & H & H' $^{\prime}$ \\
\hline OPF01 & ACGGATCCTG & 13 & 13 & 100.0 & $350-2,000$ & 0.39 & 0.57 \\
OPX01 & CTGGGCACGA & 15 & 11 & 73.3 & $300-2,000$ & 0.34 & 0.51 \\
OPF03 & CCTGATCACC & 16 & 15 & 93.8 & $300-1,500$ & 0.31 & 0.48 \\
OPW03 & GTCCGGAGTG & 12 & 11 & 91.7 & $200-2,000$ & 0.29 & 0.45 \\
OPF07 & CCGATATCCC & 15 & 15 & 100.0 & $250-2,500$ & 0.37 & 0.56 \\
OPC20 & ACTTCGCCAC & 11 & 11 & 100.0 & $400-2,000$ & 0.38 & 0.55 \\
OPC15 & GACGGATCAG & 9 & 9 & 100.0 & $250-3,000$ & 0.37 & 0.56 \\
OPF12 & ACGGTACCAG & 14 & 13 & 92.9 & $300-2,500$ & 0.40 & 0.57 \\
OPC19 & GTTGCCAGCC & 10 & 8 & 80.0 & $350-2,000$ & 0.30 & 0.46 \\
OPF10 & GGAAGCTTGG & 11 & 8 & 72.7 & $200-2,500$ & 0.40 & 0.58 \\
Mean & & 12.6 & 11.4 & 90.4 & $200-3,000$ & 0.36 & 0.53 \\
\hline Total & & 126 & 114 & & & &
\end{tabular}

$T F$ : Total fragments, $P F$ : Polymorphic fragments, \% of $P$ : percentage of polymorphic fragments, $H:$ Nei's genetic diverisity, $H^{\prime}:$ Shannon's information index, $M S R$ : Molecular size range (bp). 


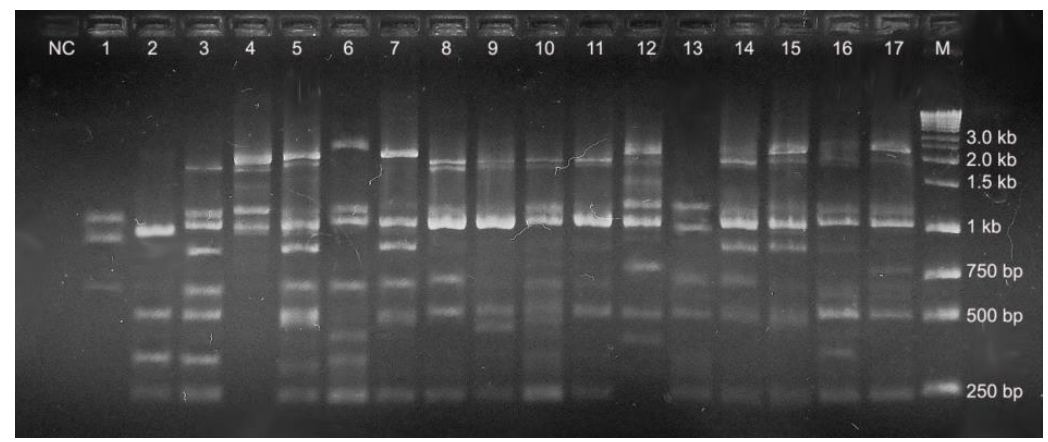

Fig 2. PCR-RAPD analysis with primer OPF07, with Lane NC: negative control, 1: G-MKd1, 2: G-MKd2, 3: G-MKd3, 4: G-MKd4, 5: G-MKd7, 6: G-MKd8, 7: G-MKd10, 8: G-MKd12, 9: G-MKd14, 10: G-MKd15, 11: G-Mkd16, 12: G-MKd18, 13: G-MKd19, 14: G-MKd20, 15: G-MKd21, 16: G-MKd22, 17: G-MKd24 and M: GeneRuler 1kb DNA ladder.

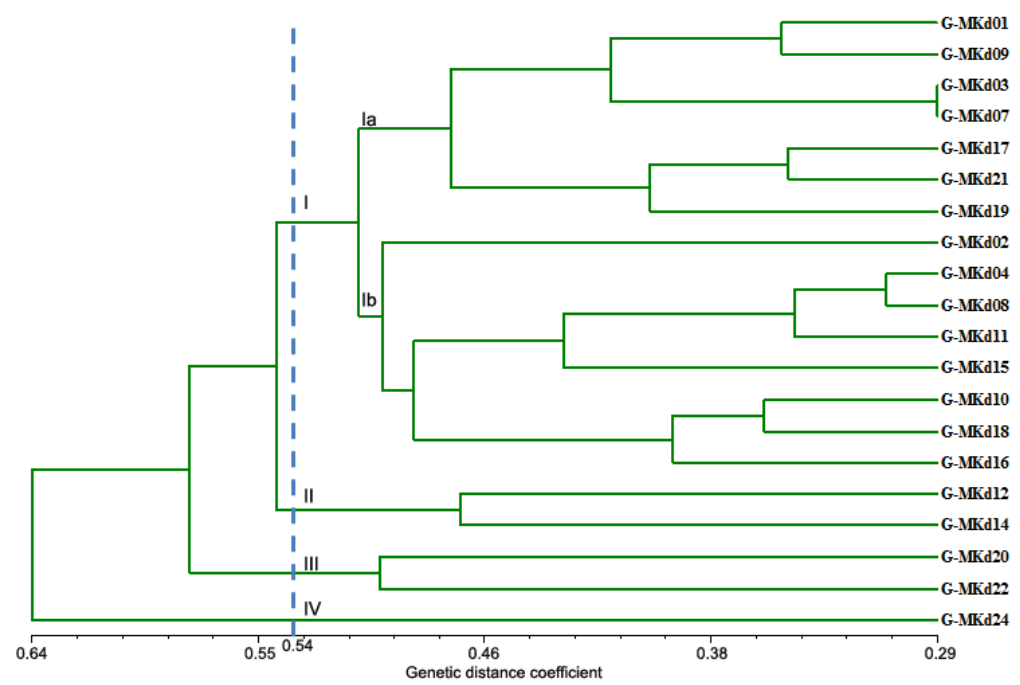

Fig 3. Dendrogram generated using UPGMA cluster analysis based on RAPD data for genetic diversity of 20 gac accessions.

correspond to the initials of the name of their collection zones (Table 1 and Fig. 1). Ten seeds from each accession were sown in plastic pots then cultivated in experimental field at Nong Lam University in Ho Chi Minh city $\left(10^{0} 52^{\prime} 12 \mathrm{~N}\right.$ $\left.106^{\circ} 47^{\prime} 12 \mathrm{E}\right)$. DNA was extracted from young leaves of 6 to 8 weeks old seedling on each individual plant using a protocol described in Warwick and Gugel (2003) with minor modification described in Pham et al. (2009).

\section{PCR-RAPD and electrophoresis}

The PCR-RAPD procedure for gac was carried out as described by Williams et al. (1990). Amplification reaction was performed in a volume of $25 \mu$ containing $1 \mathrm{X}$ PCR buffer (10 mM Tris-HCl, pH 8.3 and $50 \mathrm{mM} \mathrm{KCl}), 0.2 \mathrm{mM}$ dNTP (each of dATP, dTTP, dCTP, dGTP), $3 \mathrm{mM} \mathrm{MgCl2}$, 1U Taq polymerase (Sigma), $0.2 \mathrm{mM}$ primer (Operon Biotechnologies) and about 50-60 ng DNA template. The PCR was carried out in a thermal cycler (GeneAmp PCR Apply Biosystem 9700 , Singapore) using $5 \mathrm{~min}$ at $94{ }^{\circ} \mathrm{C}$ for denaturation followed by 40 cycles of $60 \mathrm{~s}$ at $94{ }^{\circ} \mathrm{C}, 90 \mathrm{~s}$ at $35^{\circ} \mathrm{C}$, and $180 \mathrm{~s}$ at $72{ }^{\circ} \mathrm{C}$. The cycles were followed by a final extension period of $10 \mathrm{~min}$ at $72{ }^{\circ} \mathrm{C}$. The RAPD fragments were separated on $1 \%$ agarose gel in $1 \mathrm{X}$ TAE (40 mM Tris-acetate, $\mathrm{pH} 8.0,1 \mathrm{mM}$ EDTA) buffer at 80 volt and $200 \mathrm{~mA}$ for $1 \mathrm{~h}$. GeneRuler $1 \mathrm{~kb}$ DNA ladder ranging from $250 \mathrm{bp}$ to $10 \mathrm{~kb}$ was used as a molecular weight marker. The reproducibility of the amplification products was checked three times for each primer. A negative control that contained all components of a typical reaction but lacked template
DNA was included on each gel. After electrophoresis, the gels were stained in ethidium bromide for $30 \mathrm{~min}$, and then rinsed in water for $30 \mathrm{~min}$. The gels were photographed using UV light and a Sony camera. Images were later used to score amplification products and set up the binary data.

\section{Polymorphic RAPD primers screening}

Four accessions from different place of collection (G-MKd1, G-MKd8, G-MKd16 and G-MKd20) were used for evaluating amplification level of primers. Thirty RAPD primers were collected for their ability to amplify polymorphic bands, which had previously been used in investigations by Bharathi et al. (2012) in Momordica spp. and Bootprom et al. (2012) in Momordica cochinchinensis. Ten primers amplified distinctive band in four gac accessions with good polymorphic bands. Therefore, ten primers (Table 2) were selected for PCR amplification of all accessions.

\section{Scoring and data analysis}

Each amplification product was considered as an independent character (locus) and was identified by the name of the primer and the size of the DNA amplification product. The amplified fragments in each of the 20 gac accessions were scored manually for their presence (denoted as " 1 ") or absence (denoted as " 0 ") for each primer combination. Fragment size was compared to a molecular weight $1 \mathrm{~kb}$ DNA ladder. 


\section{Genetic distance and cluster analysis}

The binary data was used to generate a similarity index (matrix) using the method based on Nei and Li (1979) genetic distance value. Genetic similarity GS $=\frac{2 N a b}{N a+N b}$ where $N a b$ is the number of fragments shared by accession $a$ and $b, N a$ is the number of fragments in accession $a$, and $N b$ is the number of fragments in accession $b$. For the analyses of genetic distances among populations, the similarity matrix was converted to a distance matrix, using formula $G D=1-G S$ or $G D=-\ln (G S)$ (Weising et al., 2005). This matrix was further employed to generate dendrogram using the unweighted pair group arithmetic average method (UPGMA).

Cluster and Neighbor joining analysis were carried out using the SAHN-UPGMA and Neighbor joining clustering method, respectively by using the Numerical Taxonomy System (NTSYSpc 2.1) software. To calculate Nei's gene diversity $(\mathrm{H})$ and Shannon diversity index $\left(\mathrm{H}^{\prime}\right)$ of phenotypic diversity for the RAPD binary data. The Popgene software version 1.31 (Yeh and Boyle, 1997) was employed.

\section{Conclusion}

In conclusion, a high genetic diversity of 20 gac accessions collected in Mekong delta of Vietnam were revealed using 10 RAPD markers. The RAPD markers also revealed high level of polymorphism (90.4\%) across the gac accessions. According to these results, RAPD technique can be useful tool in genetic diversity evaluation of Momordica cochinchinensis. The information achieved could also be used for cultivar differentiation and conservation.

\section{Acknowledgement}

This project was supported by The National Foundation for Science and Technology Development (NAFOSTED), Vietnam. The authors acknowledge Associate Professor Duong Tan Nhut at Tay Nguyen Institute of Biology for valuable advices. We are thankful to all colleagues for their assistance and support.

\section{References}

Aoki H, Kieu NTM, Kuze N, Tomisaka K, CHUYEN NV (2002) Carotenoid pigments in GAC fruit (Momordica cochinchinensis SPRENG). Biosci Biotechnol Biochem. 66 (11):2479-2482

Behera T, Gaikwad A, Saxena S, Bharadwaj C, Munshi A (2012) Morphological and molecular analyses define the genetic diversity of Asian bitter gourd (Momordica charantia L.). Aust J Crop Sci. 6 (2):261-267

Bharathi L, Parida S, Munshi A, Behera T, Raman K, Mohapatra T (2012) Molecular diversity and phenetic relationship of Momordica spp. of Indian occurrence. Genet Resour Crop Evol. 59 (5):937-948

Bhat KV, Babrekar PP, Lakhanpaul S (1999) Study of genetic diversity in Indian and exotic sesame (Sesamum indicum L.) germplasm using random amplified polymorphic DNA (RAPD) markers. Euphytica. 110 (1):21-34

Bootprom N, Songsri P, Suriharn B, Chareonsap P, Sanitchon J, Lertrat K (2012) Molecular diversity among selected Momordica cochinchinensis (Lour.) Spreng accessions using RAPD markers. Sabrao J Breed Genet. 44 (2):406-417
De Shan M, Hu L, Chen Z (2001) A new multiflorane triterpenoid ester from Momordica cochinchinensis Spreng. Nat Prod Res. 15 (2):139-145

Dey S, Singh A, Chandel D, Behera T (2006) Genetic diversity of bitter gourd (Momordica charantia L.) genotypes revealed by RAPD markers and agronomic traits. Sci Hort. 109 (1):21-28

Ercan AG, Taskin M, Turgut K (2004) Analysis of genetic diversity in Turkish sesame (Sesamum indicum L.) populations using RAPD markers. Genet Resour Crop Evol. 51 (6):599-607

Ganesh S, Thangavelu S (1995) Genetic divergence in sesame (Sesamum indicum). Madras Agric J. 82:263-265

Geleta M, Bryngelsson T, Bekele E, Dagne K (2008) Assessment of genetic diversity of Guizotia abysinica (L.f.) Cass.(Asteraceae) from Ethiopia using amplified fragment length polymorphism. Plant Genet Resour. 6 (01):41-51

Gerster H (1997) The potential role of lycopene for human health. J Am Coll Nutr. 16 (2):109-126

Gwanama C, Labuschagne M, Botha A (2000) Analysis of genetic variation in Cucurbita moschata by random amplified polymorphic DNA (RAPD) markers. Euphytica. 113 (1):19-24

Giovannucci E (1999) Tomatoes, tomato-based products, lycopene, and cancer: review of the epidemiologic literature. J Natl Cancer Inst. 91 (4):317-331

Giovannucci E, Rimm EB, Liu Y, Stampfer MJ, Willett WC (2002) A prospective study of tomato products, lycopene, and prostate cancer risk. J Natl Cancer Inst. 94 (5):391-398

Ishida BK, Turner C, Chapman MH, McKeon TA (2004) Fatty acid and carotenoid composition of gac (Momordica cochinchinensis Spreng) fruit. J Agric Food Chem. 52 (2):274-279

Iwamoto M, Okabe H, Yamauchi T, Tanaka M, Rokutani Y, Hara S, Mihashi K, Higuchi R (1985) Studies on the constituents of Momordica cochinchinensis Spreng. I. Isolation and characterization of the seed saponins, momordica saponins I and II. Chem Pharm Bull. 33 (2):464-478

Karp A, Kresovich S, Bhat KV, Ayad WG, Hodgkin T (1997) Molecular tools in plant genetic resources conservation: a guide to the technologies, vol Bull N02. International plant genetic resources institute. IPGRI tech, Rom, Italy

Koornneef M (1990) Arabidopsis thaliana genetic map. In: Brien SJ (ed) Cold spring harbor laboratory press. Cold spring Harbor, New York, pp 694-697

Kubola J, Siriamornpun S (2011) Phytochemicals and antioxidant activity of different fruit fractions (peel, pulp, aril and seed) of Thai gac (Momordica cochinchinensis Spreng). Food Chem. 127 (3):1138-1145

Liu C (1997) Geographical distribution of genetic variation in Stylosanthes scabra revealed by RAPD analysis. Euphytica. 98 (1-2):21-27

Michaud DS, Feskanich D, Rimm EB, Colditz GA, Speizer FE, Willett WC, Giovannucci E (2000) Intake of specific carotenoids and risk of lung cancer in 2 prospective US cohorts. Am J Clin Nutr. 72 (4):990-997

Mujaju C, Sehic J, Werlemark G, Garkava-Gustavsson L, Fatih M, Nybom H (2010) Genetic diversity in watermelon (Citrullus lanatus) landraces from Zimbabwe revealed by RAPD and SSR markers. Hereditas. 147 (4):142-153

Nei M, Li W-H (1979) Mathematical model for studying genetic variation in terms of restriction endonucleases. Proc Natl Acad Sci. 76 (10):5269-5273 
Pham TD, Bui TM, Werlemark G, Bui TC, Merker A, Carlsson AS (2009) A study of genetic diversity of sesame (Sesamum indicum L.) in Vietnam and Cambodia estimated by RAPD markers. Genet Resour Crop Evol. 56 (5):679690

Rafii M, Shabanimofrad M, Edaroyati MP, Latif M (2012) Analysis of the genetic diversity of physic nut, Jatropha curcas L. accessions using RAPD markers. Mol Biol Rep. 39 (6):6505-6511

Rasul M, Hiramatsu M, Okubo H (2007) Genetic relatedness (diversity) and cultivar identification by randomly amplified polymorphic DNA (RAPD) markers in teasle gourd (Momordica dioica Roxb.). Sci Hortic. 111 (3):271279

Reiter RS, Young RM, Scolnik PA, Koncz C, Chua N, Schell J (1992) Genetic linkage of the Arabidopsis genome: methods for mapping with recombinant inbreds and Random Amplified Polymorphic DNAs (RAPDs). Methods in Arabidopsis research:170-190

Sanwal S, Yadav R, Rai N, Yadav D, Singh P (2007) Genetic diversity and interrelation analysis in sweet gourd (Momordica cochinchinensis) genotypes of Northeast India. Vegetable Science. 34 (1):64-66

Soller M, Beckmann J (1983) Genetic polymorphism in varietal identification and genetic improvement. Theor Appl Genet. 67 (1):25-33

Stankiewicz M, Gadamski G, Gawronski S (2001) Genetic variation and phylogenetic relationships of triazine resistant and triazine susceptible biotypes of Solanum nigrum analysis using RAPD markers. Weed Res. 41 (4):287-300

Sureja A, Sirohi P, Behera T, Mohapatra T (2006) Molecular diversity and its relationship with hybrid performance and heterosis in ash gourd [Benincasa hispida (Thunb.) Cogn.]. J Hortic Sci Biotechnol. 81 (1):33-38
Vuong L, King J (2003) A method of preserving and testing the acceptability of gac fruit oil, a good source of $\beta$ carotene and essential fatty acids. Food Nutr Bull. 24 (2):224-230

Vuong LT, Dueker SR, Murphy SP (2002) Plasma $\beta$-carotene and retinol concentrations of children increase after a $30-d$ supplementation with the fruit Momordica cochinchinensis (gac). Am J Clin Nutr. 75 (5):872-879

Vuong LT, Franke AA, Custer LJ, Murphy SP (2006) Momordica cochinchinensis Spreng.(gac) fruit carotenoids reevaluated. J Food Comp Anal. 19 (6):664-668

Warwick SI, Gugel RK (2003) Genetic variation in the Crambe abyssinica-C. hispanica-C. glabrata complex. Genet Resour Crop Evol. 50 (3):291-305

Weising K, Nybom H, Wolff K, Kahl G (2005) Evaluation of molecular marker data. In: DNA fingerprinting in plant: Principles, methods, and applications. CRC Press, pp 207233

Williams JGK, Kubelik AR, Livak KJ, Rafalski JA, Tingey SV (1990) DNA Polymorphisms Amplified by Arbitrary Primers Are Useful as Genetic-Markers. Nucleic Acids Res. 18 (22):6531-6535

Wimalasiri D, Piva T, Urban S, Huynh T (2016) Morphological and genetic diversity of Momordica cochinchinensis (Cucurbitaceae) in Vietnam and Thailand. Genet Resour Crop Evol. 63 (1):19-33

Yeh FC, Boyle TJB (1997) Population genetic analysis of codominant and dominant markers and quantitative traits. Belgian J Bot. 129 (2):157-157 